\title{
FORECASTING OF QUALITY OF LIFE OF PATIENTS WITH FRACTURES OF THE PROXIMAL FEMUR
}

\author{
Tamara Hurbanova ${ }^{1}$ \\ ${ }^{1}$ Department of Traumatology, Anesthesiology and Military Surgery, Kharkiv Academy of Postgraduate Education, Kharkiv, Ukraine \\ ORCID: http://orcid.org/0000-0002-1019-6778
}

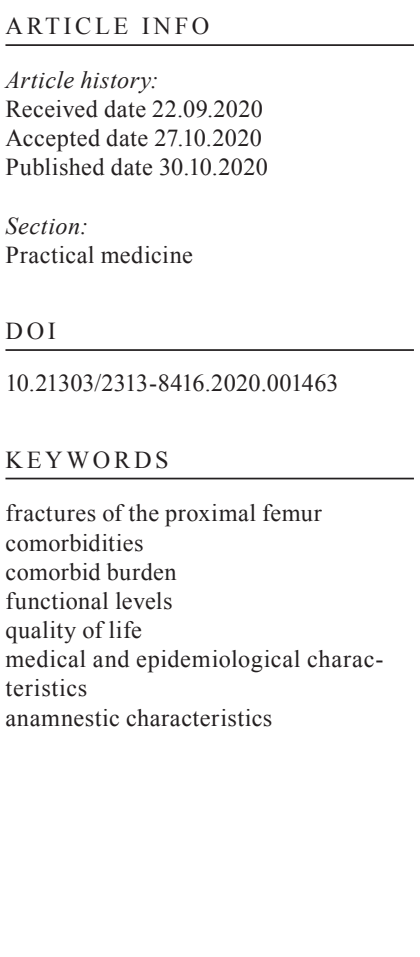

\section{ABSTRACT}

The aim of the research: correlation levels of the psychological component of quality of life and medical-epidemiological characteristics of patients with fractures of the proximal thigh.

Solved problem: to determine the possibility of predicting the impact of medical-epidemiological and anamnestic characteristics of patients with fractures of the proximal thigh on their quality of life after treatment of fractures of the proximal thigh.

Main scientific results: natural increase in comorbidity in the presence of comorbidities, low functional status and an increase in age characteristics were established. The probable influence of comorbidity on the decrease of the functional state according to the ASA classification also stated. An increase in the duration of treatment of patients with surgical treatment and a longer period of injury marked. The decrease in the quality of life of patients with increasing age characteristics, increasing comorbidity and reducing the indicators of functional status according to the ASA classification have been established.

Area of practical use of research results: medical institutions of traumatological profile. Innovative technological product: determining the ability to predict the quality of life of patients after treatment of fractures of the proximal thigh, which allows you to predict the results of treatment such patients.

Scope of application of the innovative technological product: clinical medical traumatological practice of use of possibilities of forecasting of results of treatment of fractures of proximal hip department.

(C) The Author(s) 2020. This is an open access article under the CC BY license http://creativecommons.org/licenses/by/4.0).

\section{Introduction}

\section{1. Object of research}

Correlation levels of the psychological component of quality of life and medical-epidemiological characteristics of patients with fractures of the proximal thigh.

\section{2. Problem description}

The global modern trend for steady growth of primordial significant levels of musculoskeletal apparatus diseases and injuries has numerous medical and social consequences, such as a significant share of temporary and permanent disability and mortality, high economic losses, high prevalence and primary morbidity, significant levels of DALY, etc. [1,2]. Among all diseases of the musculoskeletal system and the consequences of trauma, the bone fractures occupy first places. At the same time, the world literature data indicate a significant advantage of femoral fractures among all skeletal fractures, namely fractures of the proximal femur (further - FPF).

\section{3. Suggested way to solve the problem}

According to the literature, FPF among the entire world community in terms of its medical, social and epidemiological characteristics and consequences are the most severe among the list of all fixed injuries of the bones of the lower extremities. There are about 2 million FPF cases annually registered [3]. At the same time, according to existing forecasts, until 2050 the frequency of such fractures expected within 6-6.26 million cases [4, 5]. In Ukraine, the frequency of such fractures is also disappointing. In Ukraine, every year the diagnosis of FPF is recorded in 100-150 patients per 100 thousand population with a steady upward trend $[6,7]$. 
There is a global trend of exponential increase in frequency of FPF among older people [8]. About 140,000 intervertebral fractures are diagnosed each year, FPF among adult patients accounts for about 5.00-14.00\% of all skeletal fractures and from $32.00 \%$ to $65.00 \%$ for all hip fractures [9, 10]. Moreover, fractures of the femoral neck are found much more often $(75.30$ $80.20 \%$ ) in contrast to swivel fractures (19.80-24.70\%) [11].

Based on this, FPF requires close attention from the entire medical community. Solving this problem requires a comprehensive interdisciplinary approach that will provide answers a number of traumatological, surgical, therapeutic, social, economic and psychological issues and will eliminate the negative post-treatment risks, reduce the number of possible complications and mortality rates [12].

The aim of the research was to determine the possibility of predicting the impact of medicalepidemiological and anamnestic characteristics of patients with fractures of the proximal femur of their quality of life.

\section{Materials and methods of the research}

The study is based on the prospective study of medical-epidemiological and anamnestic characteristics of patients with fractures of the proximal femur, who were treated on the basis of the Municipal Non-Profit Enterprise "City Clinical Multidisciplinary Hospital No. 17" Kharkiv City Council in 2018-2019.

We surveyed 238 people who received FPF treatment in 2018-2019, in mean age of 70.63土 \pm 0.84 years. There were $161(67.65 \%)$ females and $77-(32.35 \%)$ males among them.

All patients signed an informed consent for voluntary participation in the study. All relevant permits and a positive decision was made by the commission on compliance with international ethical and biotic norms and requirements were obtained.

To determine physical health (PH) components and mental health (MH) components of quality of life (QOL) we used a generally accepted and adapted in Ukraine questionnaire to determine levels QOL - Short Form Medical Outcomes Study (SF-36) [13].

Evaluation of the identified individual medical-epidemiological and anamnestic characteristics of the examined groups by $\mathrm{PH}$ and $\mathrm{MH}$ components of QOL questionnaire SF-36 was performed using quartiles. For these purposes the entire sample of patients was distributed by $\mathrm{PH}$ and MH components according to questionnaire SF-36 on 4 quartiles with the following limit values: $\mathrm{PH}: \leq 21.56$ for the 1-st quartile; 21.56-22.525 - for the 2-nd quartile; 22.525-23.94 - for the 3-rd quartile and $\geq 23.94$ - for the 4-th quartile; $\mathrm{MH}: \leq 41.235$ - for the 1-st quartile; 41.235-44.425 for the 2-nd quartile; 44.235-47.9375 - for the 3-rd quartile and $\geq 47.9375$ - for the 4-th quartile. There were 59, 60, 60 and 59 patients in the subgroups which corresponded to 1-st, 2-nd, 3-rd and 4-th quartiles.

To assess the relationship between indicators between a bilateral criterion of rank correlation Spearman's R was calculated. Verification of the normality of the distribution of the trait was determined using criteria Kolmogorov-Smirnov test of normality and Shapiro-Wilk's test of normality. The level of significance threshold (error $\alpha$ ) in the work was taken at the level of $0.05(p=0.05)$ with an indication of the exact value of the level of reliability $p$. The calculation of correlation levels was performed using the application package IBM SPSS 25.0 for Windows.

\section{Results}

Correlation levels of dependence of medical-epidemiological and anamnestic characteristics and physical health $(\mathrm{PH})$ components and mental health $(\mathrm{MH})$ components of quality of life (QOL) regarding patients with FPF on quartiles of $\mathrm{MH}$ component were investigated.

For the 1st quartile (the lowest values of $\mathrm{MH}$ ) and $\mathrm{MH}$ component of the QOL were obtained features provided in Table 1.

It should be noted that in patients who had the lowest MH profile (1st quartile) there was a decrease in MN levels of the QOL component with increasing age characteristics of the examined patients with FPF (age of patients significantly inversely correlated with the average strength with of the $\mathrm{MH}$ component: $\mathrm{r}=-0.46 ; \mathrm{p}<0.001$ ), which is a natural phenomenon. It was also probably natural to note a decrease in the functional state with increasing comorbidity (significant direct average correlation of comorbidity with the functional state according to the ASA classification: 
$\mathrm{r}=0.79 ; \mathrm{p}<0.001$ ). Also, the results regarding the statement of the best functional state in connection with the absence of comorbidity diseases (CD): reliable average strength inverse correlation between the absence of $\mathrm{CD}$ and the functional state according to the ASA classification $(\mathrm{r}=-0.52$; $\mathrm{p}<0.001$ ), that also be seen as expected result. At the same time, there was an increase in the duration of hospitalization of patients during surgical treatment (the duration of hospitalization was significantly directly with the average force correlated with the type of treatment chosen: $r=0.63$; $\mathrm{p}<0.001)$ - Table 1 .

\section{Table 1}

Matrix of correlations of medical-epidemiological and anamnestic characteristics of patients of the 1st quartile on mental health $(\mathrm{MH})$ component of quality of life $(\mathrm{n}=59)$

\begin{tabular}{|c|c|c|c|c|c|c|c|c|c|c|}
\hline Indicators & & 范 & 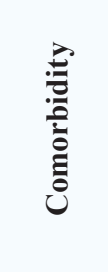 & 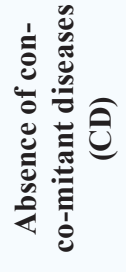 & 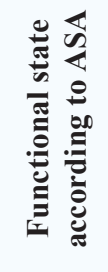 & 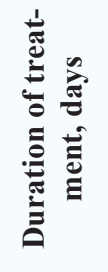 & 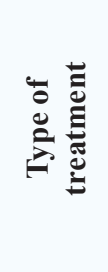 & 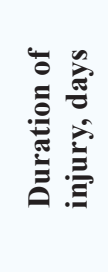 & $\underline{\pi}$ & 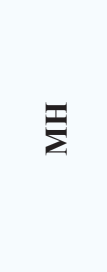 \\
\hline \multirow{2}{*}{ Age } & $\mathrm{r}$ & 1.00 & -0.06 & -0.05 & -0.10 & -0.23 & -0.10 & -0.25 & -0.10 & -0.46 \\
\hline & $\mathrm{p}$ & - & 0.65 & 0.71 & 0.44 & 0.08 & 0.45 & 0.06 & 0.43 & $<0.001$ \\
\hline \multirow{2}{*}{ Comorbidity } & $\mathrm{r}$ & -0.06 & 1.00 & -0.55 & 0.79 & 0.17 & 0.05 & 0.06 & 0.12 & 0.07 \\
\hline & $\mathrm{p}$ & 0.65 & - & $<0.001$ & $<0.001$ & 0.21 & 0.72 & 0.64 & 0.35 & 0.59 \\
\hline \multirow{2}{*}{ Absence of CD } & $\mathrm{r}$ & -0.05 & -0.55 & 1.00 & -0.52 & -0.09 & -0.12 & -0.06 & -0.12 & -0.22 \\
\hline & $\mathrm{p}$ & 0.71 & $<0.001$ & - & $<0.001$ & 0.52 & 0.38 & 0.65 & 0.38 & 0.09 \\
\hline \multirow{2}{*}{ Functional state according to ASA } & $\mathrm{r}$ & -0.10 & 0.79 & -0.52 & 1.00 & 0.10 & 0.02 & -0.01 & 0.07 & 0.08 \\
\hline & $\mathrm{p}$ & 0.44 & $<0.001$ & $<0.001$ & - & 0.47 & 0.87 & 0.96 & 0.62 & 0.52 \\
\hline \multirow{2}{*}{ Duration of treatment, days } & $\mathrm{r}$ & -0.23 & 0.17 & -0.09 & 0.10 & 1.00 & 0.63 & 0.81 & 0.18 & 0.14 \\
\hline & $\mathrm{p}$ & 0.08 & 0.21 & 0.52 & 0.47 & - & $<0.001$ & $<0.001$ & 0.18 & 0.28 \\
\hline \multirow{2}{*}{ Type of treatment } & $\mathrm{r}$ & -0.10 & 0.05 & -0.12 & 0.02 & 0.63 & 1.00 & 0.72 & 0.11 & 0.13 \\
\hline & $\mathrm{p}$ & 0.45 & 0.72 & 0.38 & 0.87 & $<0.001$ & - & $<0.001$ & 0.41 & 0.32 \\
\hline \multirow{2}{*}{ Duration of injury, days } & $\mathrm{r}$ & -0.25 & 0.06 & -0.06 & -0.01 & 0.81 & 0.72 & 1.00 & 0.06 & 0.17 \\
\hline & $\mathrm{P}$ & 0.06 & 0.64 & 0.65 & 0.96 & $<0.001$ & $<0.001$ & - & 0.66 & 0.20 \\
\hline
\end{tabular}

Note: $r$-the correlation coefficient; $p$ - the statistical significance of the difference

Correlation levels of medical-epidemiological and anamnestic indicators and levels of PH and $\mathrm{MH}$ components of patients with FPF on the 2nd quartile of the MH component (slightly higher $\mathrm{MH}$ levels) are given in Table 2.

Among patients with $\mathrm{MH}$ component of the 2nd quartile (had slightly higher levels of $\mathrm{MH}$ ), it was found that comorbidity probably affected the decrease in functional status (comorbidity directly strongly correlated with the functional state according to the ASA classification: $\mathrm{r}=0.90 ; \mathrm{p}<0.001$ ). Naturally, the best functional state was observed in the absence of CD (the presence of CD probably inversely correlated with the average force with the functional state according to the ASA classification: $\mathrm{r}=-0.46$; $\mathrm{p}<0.001$ ). In addition, there was confirmed a previously recorded increase in the duration of treatment of patients with surgical treatment and a longer period of injury (the duration of treatment correlated directly with the average force with the type of treatment: $\mathrm{r}=0.68 ; \mathrm{p}<0.001$ and probably strongly with the duration of injury: $\mathrm{r}=0.91$; $\mathrm{p}<0.001$ ) - Table 2.

Correlation analysis of patients with FPF 3rd quartile (higher MH component) for MH component recorded in Table 3. 
Table 2

Matrix of correlations of medical-epidemiological and anamnestic characteristics of patients of the 2nd quartile on mental health $(\mathrm{MH})$ component of quality of life $(n=60)$

\begin{tabular}{|c|c|c|c|c|c|c|c|c|c|c|c|}
\hline Indicators & & : & 茂 & 节 & $\begin{array}{l}0 \\
0 \\
0 \\
0 \\
0 \\
0 \\
0 \\
0 \\
0\end{array}$ & 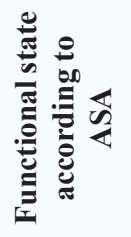 & 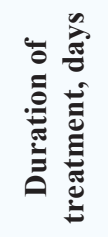 & 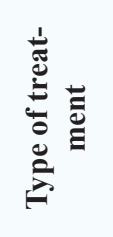 & 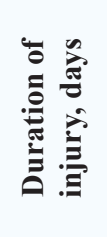 & 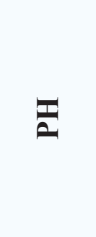 & $\Sigma$ \\
\hline \multirow{2}{*}{ Sex } & $\mathrm{r}$ & 1.00 & -0.14 & -0.19 & 0.08 & -0.17 & -0.26 & -0.10 & -0.23 & 0.07 & -0.01 \\
\hline & $\mathrm{p}$ & - & 0.28 & 0.14 & 0.57 & 0.18 & 0.04 & 0.46 & 0.08 & 0.62 & 0.91 \\
\hline \multirow{2}{*}{ Age } & $\mathrm{r}$ & -0.14 & 1.00 & $<0.001$ & 0.18 & -0.03 & -0.02 & -0.24 & -0.06 & -0.02 & 0.18 \\
\hline & $\mathrm{p}$ & 0.28 & - & 0.98 & 0.18 & 0.81 & 0.91 & 0.06 & 0.63 & 0.87 & 0.18 \\
\hline \multirow{2}{*}{ Comorbidity } & $\mathrm{r}$ & -0.19 & $<0.001$ & 1.00 & -0.42 & 0.90 & -0.01 & -0.17 & -0.09 & -0.04 & 0.11 \\
\hline & $\mathrm{p}$ & 0.14 & 0.98 & - & $<0.001$ & $<0.001$ & 0.96 & 0.20 & 0.50 & 0.74 & 0.40 \\
\hline \multirow{2}{*}{ Absence of $\mathrm{CD}$} & $\mathrm{r}$ & 0.08 & 0.18 & -0.42 & 1.00 & -0.46 & 0.11 & 0.07 & 0.10 & -0.09 & 0.14 \\
\hline & $\mathrm{p}$ & 0.57 & 0.18 & $<0.001$ & - & $<0.001$ & 0.39 & 0.62 & 0.45 & 0.49 & 0.30 \\
\hline \multirow{2}{*}{ Duration of treatment, days } & $\mathrm{r}$ & -0.26 & -0.02 & -0.01 & 0.11 & -0.04 & 1.00 & 0.68 & 0.91 & 0.08 & 0.11 \\
\hline & $\mathrm{p}$ & 0.04 & 0.91 & 0.96 & 0.39 & 0.78 & - & $<0.001$ & $<0.001$ & 0.53 & 0.42 \\
\hline \multirow{2}{*}{ Type of treatment } & $\mathrm{r}$ & -0.10 & -0.24 & -0.17 & 0.07 & -0.15 & 0.68 & 1.00 & 0.70 & 0.10 & 0.06 \\
\hline & $\mathrm{p}$ & 0.46 & 0.06 & 0.20 & 0.62 & 0.25 & $<0.001$ & - & $<0.001$ & 0.45 & 0.65 \\
\hline
\end{tabular}

Note: $r$ - the correlation coefficient; $p$ - the statistical significance of the difference

Table 3

Matrix of correlations of medical-epidemiological and anamnestic characteristics of patients of the 3rd quartile on mental health (MH) component of quality of life $(n=60)$

\begin{tabular}{|c|c|c|c|c|c|c|c|c|c|c|c|}
\hline Indicators & & $\underset{4}{*}$ & 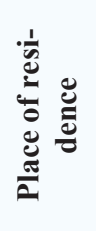 & 总 & 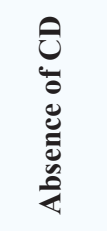 & 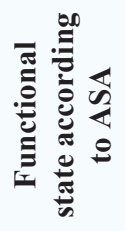 & 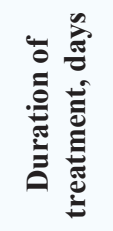 & 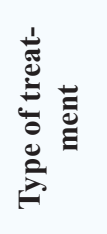 & 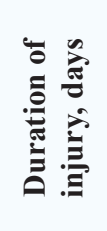 & $\bar{a}$ & $\Sigma$ \\
\hline \multirow{2}{*}{ Age } & $\mathrm{r}$ & 1.00 & -0.22 & $<0.001$ & -0.22 & $<0.001$ & -0.29 & -0.10 & -0.25 & -0.17 & -0.17 \\
\hline & $\mathrm{p}$ & - & 0.09 & 0.98 & 0.09 & 0.99 & 0.02 & 0.47 & 0.05 & 0.19 & 0.19 \\
\hline \multirow{2}{*}{ Place of residence } & $\mathrm{r}$ & -0.22 & 1.00 & 0.09 & -0.05 & 0.09 & 0.25 & 0.10 & 0.23 & 0.30 & 0.17 \\
\hline & $\mathrm{p}$ & 0.09 & - & 0.50 & 0.69 & 0.50 & 0.06 & 0.46 & 0.07 & 0.02 & 0.19 \\
\hline \multirow{2}{*}{ Comorbidity } & $\mathrm{r}$ & $<0.001$ & 0.09 & 1.00 & -0.64 & 0.75 & -0.04 & -0.02 & -0.01 & -0.04 & 0.18 \\
\hline & $\mathrm{p}$ & 0.98 & 0.50 & - & $<0.001$ & $<0.001$ & 0.76 & 0.90 & 0.97 & 0.78 & 0.16 \\
\hline \multirow{2}{*}{ Absence of CD } & $\mathrm{r}$ & -0.22 & -0.05 & -0.64 & 1.00 & -0.63 & -0.02 & -0.12 & -0.05 & -0.04 & 0.04 \\
\hline & $\mathrm{p}$ & 0.09 & 0.69 & $<0.001$ & - & $<0.001$ & 0.91 & 0.37 & 0.71 & 0.75 & 0.75 \\
\hline \multirow{2}{*}{ Duration of treatment, days } & $\mathrm{r}$ & -0.29 & 0.25 & -0.04 & -0.02 & 0.02 & 1.00 & 0.49 & 0.80 & 0.25 & 0.11 \\
\hline & $\mathrm{p}$ & 0.02 & 0.06 & 0.76 & 0.91 & 0.91 & - & $<0.001$ & $<0.001$ & 0.06 & 0.39 \\
\hline \multirow{2}{*}{ Type of treatment } & $r$ & -0.10 & 0.10 & -0.02 & -0.12 & 0.24 & 0.49 & 1.00 & 0.62 & 0.18 & 0.01 \\
\hline & $\mathrm{p}$ & 0.47 & 0.46 & 0.90 & 0.37 & 0.07 & $<0.001$ & - & $<0.001$ & 0.17 & 0.95 \\
\hline \multirow{2}{*}{ Duration of injury, days } & $\mathrm{r}$ & -0.25 & 0.23 & -0.01 & -0.05 & 0.15 & 0.80 & 0.62 & 1.00 & 0.30 & 0.07 \\
\hline & $\mathrm{p}$ & 0.05 & 0.07 & 0.97 & 0.71 & 0.25 & $<0.001$ & $<0.001$ & - & 0.02 & 0.61 \\
\hline
\end{tabular}

Note: $r$ - the correlation coefficient; $p$ - the statistical significance of the difference 
In general, patients of the 3 rd quartile on the $\mathrm{MH}$ component were characterized by a natural increase in comorbidity in the presence of $\mathrm{CD}$ (comorbidity significantly inversely correlated with the average force with the absence of $\mathrm{CD}: \mathrm{r}=-0.64 ; \mathrm{p}<0.001)$ and low functional status strong correlation of comorbidity with the functional state according to the ASA classification: $r=0.75$; $p<0.001$ ). Naturally, the best functional state was observed in the absence of CD (the absence of CD significantly correlated with the average force with the functional state according to the ASA classification: $r=-0.63 ; p<0.001)$. There was a natural increase in the length of stay of patients in the clinic during surgery (duration of hospitalization had a probable direct medium correlation with the type of treatment chosen: $r=0.49 ; \mathrm{p}<0.001$ ) and longer duration of injury (significant direct strong correlation of treatment duration and duration of injury: $r=0.80 ; p<0.001$ ) - Table 3 .

The last quartile analysis for the MH component (higher levels of the MH component) was performed among patients with FPF of the 4th quartile - Table 4.

\section{Table 4}

Matrix of correlations of medical-epidemiological and anamnestic characteristics of patients of the 4th quartile on MN component of quality of life $(n=59)$

\begin{tabular}{|c|c|c|c|c|c|c|c|c|c|c|c|}
\hline Indicators & & $\stackrel{\vec{D}}{\mathscr{D}}$ & $\underset{\alpha}{80}$ & 莽 & 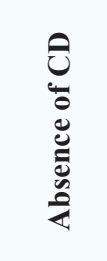 & 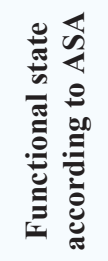 & 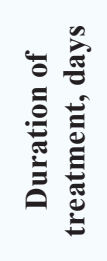 & 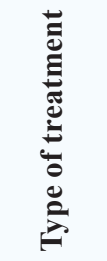 & 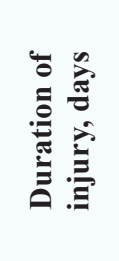 & $\underline{a}$ & $\mathbb{\Sigma}$ \\
\hline \multirow{2}{*}{ Sex } & $\mathrm{r}$ & 1.00 & 0.38 & 0.25 & -0.32 & 0.29 & 0.08 & 0.18 & $<0.001$ & -0.40 & -0.17 \\
\hline & $\mathrm{p}$ & - & $<0.001$ & 0.05 & 0.01 & 0.03 & 0.55 & 0.16 & 0.99 & $<0.001$ & 0.20 \\
\hline \multirow{2}{*}{ Age } & $\mathrm{r}$ & 0.38 & 1.00 & 0.41 & -0.31 & 0.53 & -0.03 & -0.05 & -0.08 & -0.84 & -0.67 \\
\hline & $\mathrm{p}$ & $<0.001$ & - & $<0.001$ & 0.01 & $<0.001$ & 0.82 & 0.71 & 0.57 & $<0.001$ & $<0.001$ \\
\hline \multirow{2}{*}{ Comorbidity } & $\mathrm{r}$ & 0.25 & 0.41 & 1.00 & -0.79 & 0.87 & 0.14 & 0.26 & 0.15 & -0.29 & -0.40 \\
\hline & $\mathrm{p}$ & 0.05 & $<0.001$ & - & $<0.001$ & $<0.001$ & 0.30 & 0.05 & 0.27 & 0.02 & $<0.001$ \\
\hline \multirow{2}{*}{ Absence of CD } & $\mathrm{r}$ & -0.32 & -0.31 & -0.79 & 1.00 & -0.74 & -0.07 & -0.19 & -0.02 & 0.22 & 0.24 \\
\hline & $\mathrm{p}$ & 0.01 & 0.01 & $<0.001$ & - & $<0.001$ & 0.61 & 0.16 & 0.87 & 0.10 & 0.06 \\
\hline \multirow{2}{*}{ Functional state according to ASA } & $\mathrm{r}$ & 0.29 & 0.53 & 0.87 & -0.74 & 1.00 & 0.13 & 0.18 & 0.09 & -0.44 & -0.52 \\
\hline & $\mathrm{p}$ & 0.03 & $<0.001$ & $<0.001$ & $<0.001$ & - & 0.32 & 0.17 & 0.49 & $<0.001$ & $<0.001$ \\
\hline \multirow{2}{*}{ Duration of treatment, days } & $\mathrm{r}$ & 0.08 & -0.03 & 0.14 & -0.07 & 0.13 & 1.00 & 0.70 & 0.87 & -0.10 & -0.09 \\
\hline & $\mathrm{p}$ & 0.55 & 0.82 & 0.30 & 0.61 & 0.32 & - & $<0.001$ & $<0.001$ & 0.45 & 0.49 \\
\hline \multirow{2}{*}{ Type of treatment } & $\mathrm{r}$ & 0.18 & -0.05 & 0.26 & -0.19 & 0.18 & 0.70 & 1.00 & 0.71 & -0.04 & -0.06 \\
\hline & $\mathrm{p}$ & 0.16 & 0.71 & 0.05 & 0.16 & 0.17 & $<0.001$ & - & $<0.001$ & 0.76 & 0.67 \\
\hline
\end{tabular}

Note: $r$ - the correlation coefficient; $p$ - the statistical significance of the difference

It should be noted that for patients of the 4th quartile on the MH component of QOL with increasing age characteristics was characterized by an increase in comorbidity (age significantly directly with the average force correlated with comorbidity: $r=0.41 ; p<0.001$ ), a decrease in functional status (mean strength correlation of age and functional state according to the ASA classification: $\mathrm{r}=0.53 ; \mathrm{p}<0.001$ ) and decrease in $\mathrm{PH}$ and $\mathrm{MH}$ levels of QOL components (significant inverse mean strength correlation of age with $\mathrm{PH}$ and $\mathrm{MH}$ components of QOL: respectively $\mathrm{r}=-0.84$; $\mathrm{p}<0.001$ and $\mathrm{r}=-0.67 ; \mathrm{p}<0.001)$. These patients were naturally characterized by an increase in comorbidity in the presence of $\mathrm{CD}$ (comorbidity significantly inversely correlated with the absence of $\mathrm{CD}: \mathrm{r}=-0.79 ; \mathrm{p}<0.001$ ) and with a decrease in functional status (direct strong significant correlation of comorbidity with functional status according to the ASA classification: $r=0.87 ; p<0.001$ ). There 
was also a natural probable decrease in the levels of $\mathrm{pH}$ and $\mathrm{MN}$ of the components of the QOL with increasing comorbidity (inverse weak correlation of comorbidity significantly with the PH and MH components: respectively $r=-0.29 ; p=0.02$ and $r=-0.40 ; p<0.001)$. In addition, it was natural to increase the functional parameters in the absence of CD (the absence of CD was significantly inversely correlated with the functional state according to the ASA classification: $r=-0.74 ; p<0.001$ ). It was determined decrease in $\mathrm{PH}$ and $\mathrm{MH}$ of the components of the QOL with a decrease in the functional state (functional state according to the ASA classification with the average strength was significantly inversely correlated with the $\mathrm{PH}$ and $\mathrm{MH}$ components QOL: respectively $\mathrm{r}=-0.44$ $(\mathrm{p}<0.001)$ and $\mathrm{r}=-0.52(\mathrm{p}<0.001)$ and an increase in the length of stay of patients in the clinic during surgical treatment and a longer period of injury (a direct strong correlation is likely between the duration of treatment and the type of treatment chosen and the duration of injury: respectively $\mathrm{r}=0.70$ and $\mathrm{r}=0.87, \mathrm{p}<0.001)$ - Table 4.

\section{Discussion}

Our results on the impact of certain medical-epidemiological and anamnestic characteristics of patients with fractures of the proximal thigh at the level of their quality of life after treatment are fully consistent with the data obtained during other similar studies [14-16]. According to the results of the study, it was determined that with increasing age characteristics there is a decrease of QOL; increase in comorbidity and decrease in functional state. At the same time, was observed there was an increase in the duration of hospitalization of patients during surgical treatment.

Study limitations. Some inaccuracies in the subjective assessment of the psychological limitations of the quality of life by individual patients are possible. These inaccuracies do not have a significant impact on the overall levels of the psychological component of the quality of life at the regional level.

Prospects for further research. Subsequent clinical studies will be conducted to establish the forecasted models of determination of post-treatment levels of physical and mental health (psychological) components of quality of life in patients with fractures proximal hips.

\section{Conclusions}

1. With increasing age characteristics of the examined patients, a decrease in the level of $\mathrm{MH}$ (significant mean inverse correlation of an increase in the age characteristics of patients and an increase in the MN level of QOL components: $(r=-0.46 ; p<0.001)-1$ st quartile; $(r=-0.67$; $\mathrm{p}<0.001)$ - 4th quartile) and PH (probable significant mean inverse correlation of increase in age characteristics and increase in PH components of QOL: $(r=-0.84 ; p<0.001)-4$ th quartile) components of QOL were determined.

2. An increase in comorbidity with increasing age characteristics of patients with hip fracture (reliable moderate strength correlation the increase in age characteristics and an increase in the presence of comorbidities: $(r=0.41 ; p<0.001)-4$ th quartile) stated.

3. A decrease of functional status of patients in the presence of concomitant morbidity (significant direct mean correlation of greater comorbidity and low functional status according to the ASA classification: $(\mathrm{r}=0.79 ; \mathrm{p}<0.001)$ - 1st quartile) was determined. An increase of age characteristics (average strength is likely direct correlation of increase in age characteristics and decrease in functional state according to ASA classification: $(\mathrm{r}=0.53 ; \mathrm{p}<0.001)$ - 4th quartile) and comorbidity (reliable direct strong correlation of increase in comorbidity and decrease in functional state according to ASA classification: $(r=0.87 ; \mathrm{p}<0.001)$ - 4th quartile) also stated.

4. The impact of comorbidity on the decrease in functional status (probable strong direct correlation of existing comorbidities with a decrease in functional status according to the ASA classification: $r=0.90 ; p<0.001-2$ nd quartile; $r=0.75 ; p<0.001-3$ rd quartile) was recorded.

5. An increase in the duration of hospitalization of patients during surgical treatment (moderate strength is a direct correlation of the increase in the duration of hospitalization with surgical treatment: $(\mathrm{r}=0.63 ; \mathrm{p}<0.001)$ - 1st quartile; $(\mathrm{r}=0.68 ; \mathrm{p}<0.001)-2$ nd quartile; $(\mathrm{r}=0.49 ; \mathrm{p}<0.001)-$ 3rd quartile; $(\mathrm{r}=0.70 ; \mathrm{p}<0.001)-4$ th quartile) stated.

6. Definitely significant decreases in $\mathrm{pH}$ and $\mathrm{MN}$ of QOL components with a decrease in functional state (mean force significant inverse correlation of decrease in functional state according to ASA classification and increase in $\mathrm{pH}$ and $\mathrm{MN}$ levels of QOL components: respectively 
$\mathrm{r}=-0.44(\mathrm{p}<0.001)$ and $\mathrm{r}=-0.52(\mathrm{p}<0.001)-4$ th quartile $)$ and with increasing comorbidity (inverse significant probable weak correlation of increasing comorbidity and increasing levels of $\mathrm{pH}$ and MN of QOL components: respectively $r=-0.29 ; p=0.02$ and $r=-0.40 ; p<0.001-4$ th quartile) were determined.

\section{Conflicts of interest}

The authors declare that they have no conflicts of interest.

\section{References}

[1] Kalchenko, A. V. (2019). Our experience of application of single-pole endoprosthesis in the proximal femur fractures in the elderly and senile patients. Trauma, 20 (3), 42-48. doi: http://doi.org/10.22141/1608-1706.3.20.2019.172092

[2] Titov, R. S., Fine, A. M., Vaza, A. Y., Bogolubskii, Y. A., Mazhorova, I. I., Bondarev, V. B., Sergeev, A. Y. (2019). Comparative analysis of treatment of patients with neck fractures of the femur. Physical and Rehabilitation Medicine, Medical Rehabilitation, 1 (4), 20-26. doi: http://doi.org/10.36425/2658-6843-2019-4-20-26

[3] NTDB Annual Report 2011 (2011). Chicagoo, Illinois: American College of Surgeons, 157 p. American College of Surgeons. Available at: https://www.facs.org/ /media/files/quality \%20programs/trauma/ntdb/ntdbannualreport2011.ashx

[4] Cook, A. C., Joseph, B., Inaba, K., Nakonezny, P. A., Bruns, B. R., Kerby, J. D. et. al. (2016). Multicenter external validation of the Geriatric Trauma Outcome Score: a study by the prognostic assessment of life and limitations after trauma in the elderly (PALLIATE) consortium. Journal of Trauma and Acute Care Surgery, 80 (2), 204-209. doi: http://doi.org/10.1097/ ta.0000000000000926

[5] Lee, D. R., Lee, J., Rota, M., Lee, J., Ahn, H. S., Park, S. M., Shin, D. (2014). Coffee consumption and risk of fractures: A systematic review and dose-response meta-analysis. Bone, 63, 20-28. doi: http://doi.org/10.1016/j.bone.2014.02.007

[6] Gaba, S., Agrawal, P., Das, S., Singh, R., Kumar, A., Yadav, G. (2017). Dynamic hip screw versus proximal femur locking compression plate in intertrochanteric femur fractures (AO 31A1 and 31A2): A prospective randomized study. Journal of Natural Science, Biology and Medicine, 8 (1), 87-93. doi: http://doi.org/10.4103/0976-9668.198352

[7] Patel, N. K., Sarraf, K. M., Joseph, S., Lee, C., Middleton, F. R. (2013). Implementing the National Hip Fracture Database: An audit of care. Injury, 44 (12), 1934-1939. doi: http://doi.org/10.1016/j.injury.2013.04.012

[8] Nirula, R., Gentilello, L. M. (2004). Futility of resuscitation criteria for the «young» old and the «old» old trauma patient: a National Trauma Data Bank analysis. The Journal of trauma, 57 (1), 37-41. doi: http://doi.org/10.1097/01.ta.0000128236.45043.6a

[9] Attum, B., Pilson, H. (2020). Intertrochanteric Femur Fracture. Florida: StatPearls Publishing.

[10] Miller, G. W., Godrey, J. J., Sagmeister, M. L., Lewis, T. L. (2016). Provision of fascia iliaca compartment block in the acute management of proximal femoral fractures: A national observational study of UK hospitals. Injury, 47 (11), $2490-2494$. doi: http://doi.org/10.1016/j.injury.2016.09.003

[11] Andreeva, T. M., Ohrizko, E. V., Popova, M. M. (2017). Travmatyzm, ortopedycheskaia zabolevaemost, sostoianye travmatoloho-ortopedycheskoi pomoshchy naselenyiu Rossyy v 2016 h. Moscow: Mynysterstvo Zdravookhranenyia Rossyiskoi Federatsyy, 149.

[12] Miller, B. J., Callaghan, J. J., Cram, P., Karam, M., Marsh, J. L., Noiseux, N. O. (2014). Changing Trends in the Treatment of Femoral Neck Fractures. The Journal of Bone and Joint Surgery, 96 (17), e149. doi: http://doi.org/10.2106/jbjs.m.01122

[13] Kryvenko, V. I., Kachan, I. S., Pakhomova, S. P., Fedorova, O. P., Kolesnyk, M. Yu., Nepriadkina, I. V., Hrinenko, T. Yu. (2015). Yakist zhyttia ta prykhylnist do likuvannia v klinitsi vnutrishnikh khvorob. Zaporizhzhia: Zaporizkyi derzhavnyi medychnyi universytet, 80.

[14] Marsault, L. V., Ryg, J., Madsen, C. F., Holsgaard-Larsen, A., Lauritsen, J., Schmal, H. (2020). Objectively Measured Physical Activity and Its Association with Functional Independence, Quality of Life and In-Hospital Course of Recovery in Elderly Patients with Proximal Femur Fractures: A Prospective Cohort Study. Rehabilitation Research and Practice, $2020,1-10$. doi: http://doi.org/10.1155/2020/5907652

[15] Campenfeldt, P., Ekström, W., Al-Ani, A. N., Weibust, E., Greve, K., Hedström, M. (2020). Health related quality of life and mortality 10 years after a femoral neck fracture in patients younger than 70 years. Injury, 51 (10), 2283-2288. doi:10.1016/ j.injury.2020.06.029

[16] Amarilla-Donoso, F. J., López-Espuela, F., Roncero-Martín, R., Leal-Hernandez, O., Puerto-Parejo, L. M., Aliaga-Vera, I. et. al. (2020). Quality of life in elderly people after a hip fracture: a prospective study. Health and Quality of Life Outcomes, 18 (1). doi: http://doi.org/10.1186/s12955-020-01314-2 